\title{
The Albanian School Facing the Difficulties for an Education Close to the Needs of the Children with Special Needs.
}

Doc. Dr. Ambera DUKA

ambaduka@yahoo.com

MSc. Ermira TATI

sterlatati@yahoo.com

\begin{abstract}
The inclusion in education, is defined as the most favorable mean that creates the equal opportunities in education for all the children, with or without disabled abilities. The increase of the number of children with special needs and especially with those with autism within the classes, but this is followed with new challenges for the teachers of the inclusive classes in the Albanian schools. The problems of the teaching task of the teachers in these classes are a lot, but to minimize them the teaching process worldwide is paying too much favorable space by analyzing and orientations to make these problems a bit slighter. This research aims to be an empirical survey, while from its nature and condition to be qualitative. For the collection of the datas and statistics are used observations, interviews and focus groups. And as for the target group are considered the classes and the teachers that have in their members students with autism.
\end{abstract}

Keywords: the differentiated teaching, suitability, inclusive classes.

\section{Introduction}

In the Albanian reality, some of the causes that influence and make some classes face some difficulties are:

- $\quad$ The existence of more than two students with special need within the class (cases when in the class are included even students with special needs without being diagnosed or being diagnosed but the parent this fact );

- $\quad$ The great number of students (35-40) within a class together with the existence of the students with special needs ;

- $\quad$ The lack of cooperation school-family-children (cases when the parent denies the limitation of the child ). The awareness of the parent to accept that his child as he or she really is and the exact diagnosing of the child for the symptoms that he demonstrate since the early childhood. The fact that the parent does not accept the reality of his or her child hardens the work of the teacher because in this way the cooperation of the teacher -parent in these cases is very necessary;

- $\quad$ The supply of the students with special needs with IEP, makes it difficult the intriguing role of the student in the educational process even the work of the teacher for a differentiated teaching and well-planned.

- $\quad$ The work of only one teacher in the classes where are integrated these children makes it difficult to teach not only for the students with special needs but even for the other students as well.

The interference and the improvement of these elements will bring about a distinguishing influence in the efficient teaching process these classes, because this is one of the priorities that makes the Albanian education face the new challenges in the reality of the Albanian schools. in. 
Teaching in these classes needs its suitability according to the needs and the abilities that each student possesses in order to study. But this suitability should have a scientific base and teaching should be more and more efficient.

\section{Literature review}

The rate of belief ${ }^{1}$ on the teacher in the integration of the students with special needs in the educational process noticed in the Albanian education, defines the level of success in the inclusive program. This rate of belief on the teacher is influenced from the perception that the teachers have in this integration, from which depends the success or not success of the inclusion , but claiming partly for the integration of the children with hard limitations. ${ }^{2}$.

The willing of the teachers for a teaching too close to the needs and the abilities that the students have got ${ }^{3}$, requires a total engagement and a devotion of; creative thinking anf effective strategies in the class in the way that this participation in the Albanian education needs the involvement of all the teachers regarding the knowledge of all the Special Abilities in order to suit better and efficiently the techniques and the teaching methods in these classes based on the contemporary technology (if the class is equipped). Taking into consideration all the techniques and practices of the other countries which is so supportive for the teacher of the class where these students are included, but it is too supportive even for the students with special needs where this student is shown accompanied by the special teacher and at the same time other support compared this with the Albanian practice in these classes where the reality is something different, the students with special needs are not accompanied by a special teacher.

\section{The methodology of the research}

This research is a qualitative research, where step by step will be shown its components. They are: the methods of selection of the participants in the research ; guide of the interview ;the participants of the research , ${ }^{4}$ and the focus-group; the method of the registration of the datas and the analysis of the datas collected (from the interview and the focus-group).

The question in the research:

- To what degree is the rate of the belief and the attitude of the teachers concerning the possibility and the abilities that they have regarding the inclusion of the students with special needs in their integration in the teaching process?

- Do the ways of evaluation of these students influence in the softening of the problems that this integration offers?

- $\quad$ Does it seem efficient to suit the teaching process with the abilities and the needs of the students with special needs in the inclusive classes?

As the intention of this research is the exploration of the phenomenon in a much deeper scale (and not the creation of a representative statistical variable), to select the participated teachers in the interviews half-structured and the participants in the focus -group is used the method of the variable with intensity (this has to do with the selection of the cases that are strong representative of the phenomena that is going to be studied. In a concrete way the variable was focused on these schools where the number of the students with special needs was considerable. The datas on the wide spreading of the students with special needs within the schools were taken from the statistical office of the Educational Regional Office of three regions: 1-Tirana; 2-Durrësi; 3-Berati.

The variable for the interviews were based on three schools of the three regions where are involved 51 teachers.

\footnotetext{
${ }_{1}^{1}$ Prakash, S.S. (2012). Inclusion of Children with Hearing Impairment in Schools: A Survey on Teachers' Attitudes. Prakash. Vol. 23, No.3, p 90-103.

${ }^{2}$ Subban, P \& Sharma, U.(2005). Understanding Educator Attitudes Toward the Implementation of Inclusive Education. Monash University, Melbourne, Victoria, Australia.

${ }_{3}^{3}$ Villa, R. A, \& Thousand, J. S. (2003). Making Inclusive Education Work. Teaching All Students, 61(2), 19-23.

${ }^{4}$ Matthews. B, \& Ross. L, (2010). "Metodat e hulumtimit", Udhëzues praktik për shkencat sociale dhe humane, Botim i CDE, Tiranë/Albani. Fq. 218-233.
} 
In the same way it is acted even for the organization of the focus-group where are involved teachers of the public and non public schools that have in their classes students with special needs or who had experienced teaching in classes where students with special needs were included. There were about 16 participants.

To collect the qualitative datas it is created a half-structured interview.

The main target of the interview was to collect a wide information in connection with the problems that is faced the inclusive teaching in the classes of the three schools. The interview consisted of 5sessions and this is used to let the interviewees to organize their answers. The interviewees was created the possibility to express "suggestions" or "renew" that they think about an efficient teaching in the classes where there are students with special needs.

\section{The method of analyzing the qualitative data.}

For the questions of the research was performed the thematic analysis. The following table shows in a collected way: Topic; Categories-Sub/Categories.

Table 1: The theme analysis for the questions of the research: Topic; Categories-Sub/Categories.

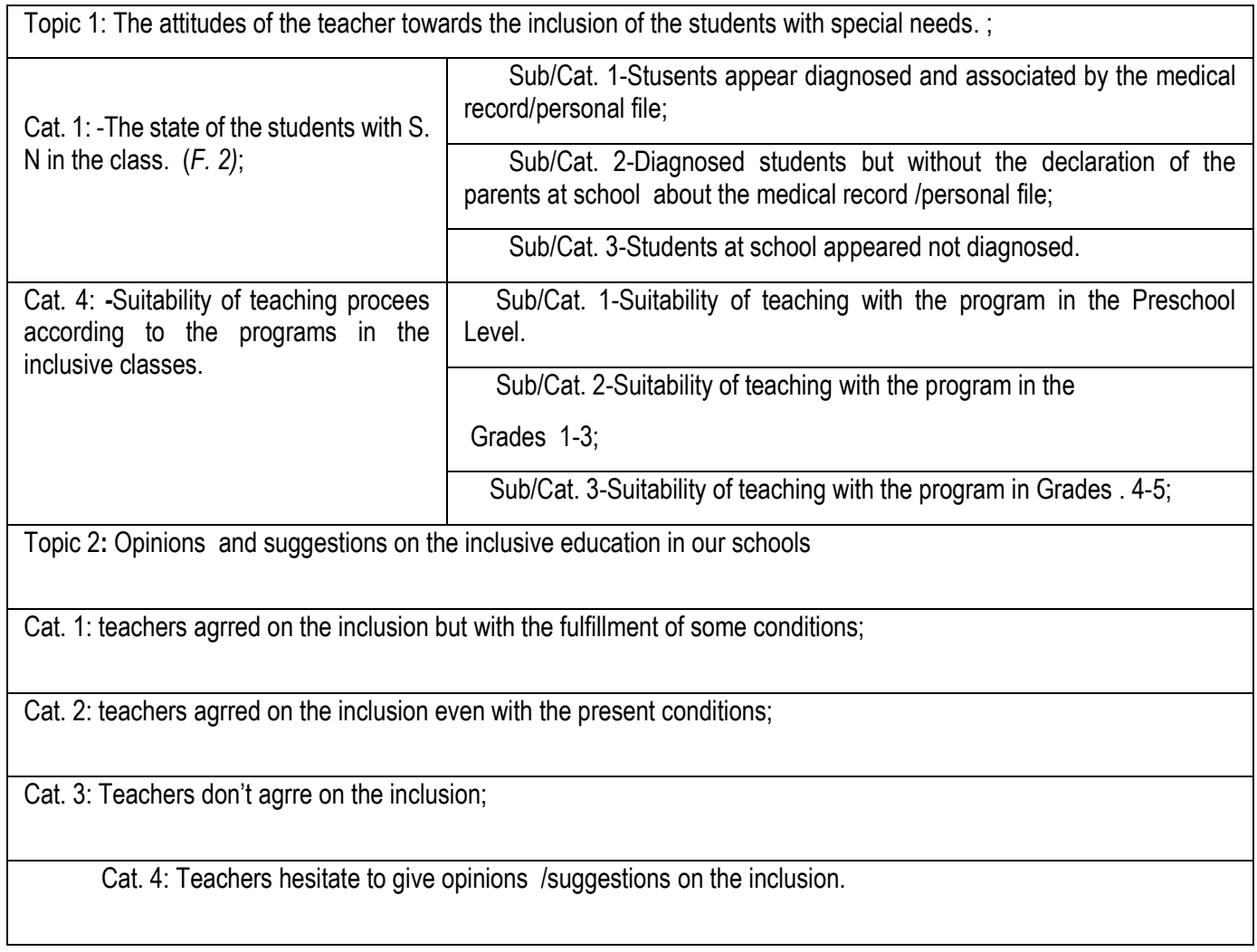

\section{The results of the research}

The results obtained from the analysis of interviews and focus-group-t

The interviews conducted with teachers of the three schools were analyzed separately, each of which time the performance of each interview was approximately 10 minutes. 
Table with full details about schools in the study for each respondent regarding the custody class, number of students with disabilities that were involved.

Table 2. Data above the participants in the intervievees

\begin{tabular}{|l|l|l|l|l|}
\hline Region & School & $\begin{array}{l}\text { Nr. of teachers in } \\
\text { the preschool } \\
\text { program }\end{array}$ & Nr. of teachers in EL & $\begin{array}{l}\text { Nr. Of teachers } \\
\text { in total }\end{array}$ \\
\hline Durrës & $\begin{array}{l}\text { School (1) } \\
\text { 'Kushtrimi I Lirisë' }\end{array}$ & 1 teacher & 15 teachers & 16 teachers \\
\hline Tiranë & $\begin{array}{l}\text { School (2) 'Emin } \\
\text { Duraku' }\end{array}$ & 2 teachers & 21 teachers & 23 teachers \\
\hline Berat & $\begin{array}{l}\text { School (3) '1 } \\
\text { Maji' }\end{array}$ & 1 teacher & 11 teacher & 12 teacher \\
\hline Total & 3 Schools & 4 teachers & 47 teachers & 51 teachers \\
\hline
\end{tabular}

The following table provides information to participants in the focus groups about the position or program that teachers ran: The data were derived served the analysis, which will be developed step by step as set forth in the interview / focus group, which will be argued in detail in the chapter.

Demographic characteristic

Data from flaring experience in teaching the teachers at P. L -dents is significant, as can be seen in the next table:

Table 3. Experience in teaching

\begin{tabular}{|l|l|l|}
\hline Experience in teaching & Interviews $(n=51)$ & Focus-Group $(n=16)$ \\
\hline Till 5 years & $12 \%$ & $12 \%$ \\
\hline $6-10$ years & $4 \%$ & $12 \%$ \\
\hline $11-20$ years & $27 \%$ & $38 \%$ \\
\hline Over 20 years & $57 \%$ & $38 \%$ \\
\hline
\end{tabular}

In relation to the number of students with disabilities school-based, data collected from interviews with teachers of the three schools, emerges a discrepancy between the number of students with disabilities declared by DAR-s offices and the real number of students with disabilities in classrooms. Here's how it appears this situation: 


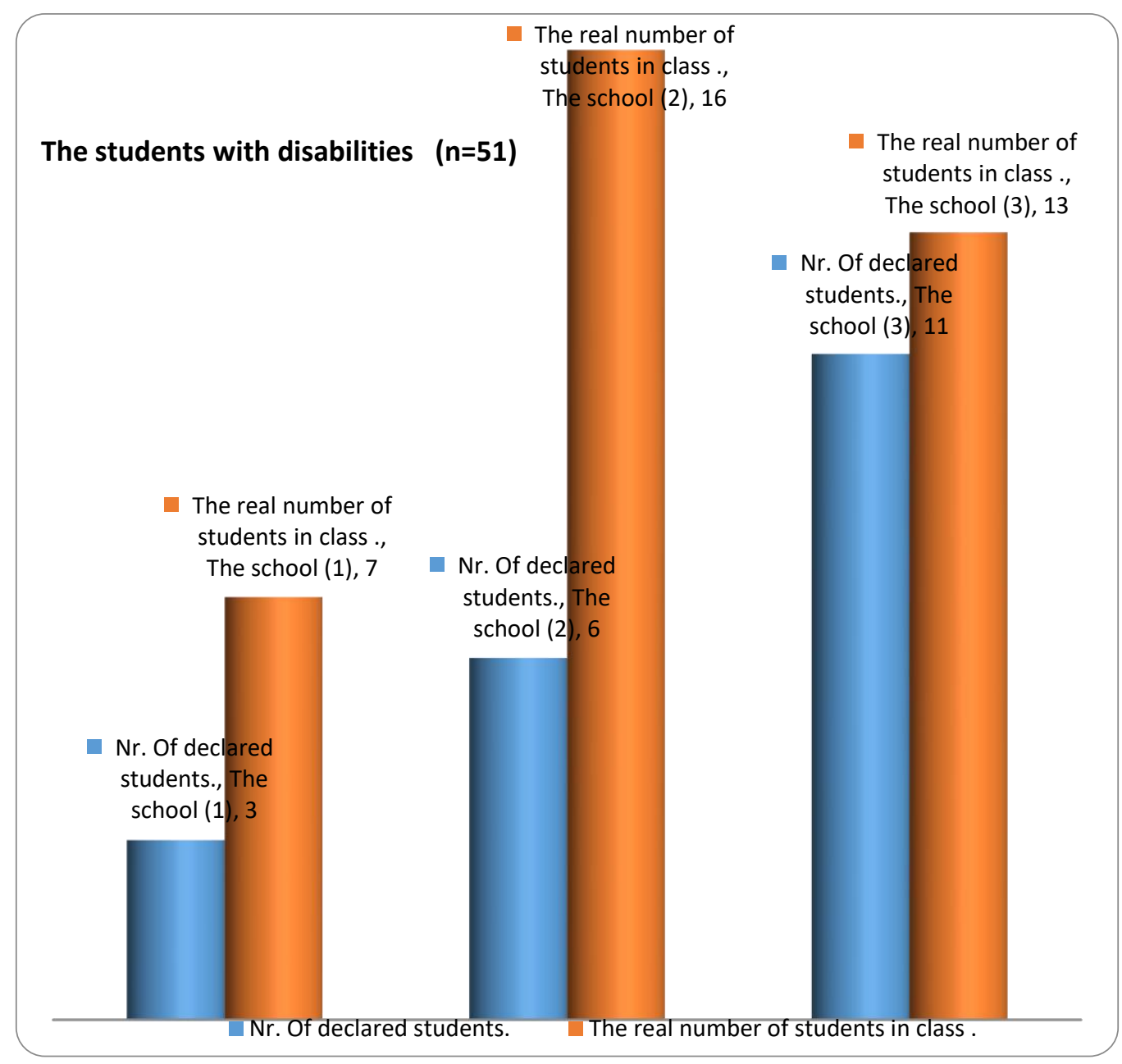

Figure 1: The students with disabilities

Findings from thematic analysis:

How do the teachers' level of trust in the opportunities and skills that they have about the inclusion of disabled students success their integration in teaching time?

Do the evaluation methods of these students, in mitigation of problems that offers this integration at teaching?

Does adaptation of teaching in the skills and needs of disabled students inclusive classrooms

Regarding the first topic on: attitudes of teachers toward inclusion of students with disabilities in the classroom, through the following schedule given this presentation expressed in \%: 


\section{The Topic 1: The students with disabilities in class $(n=36)$}

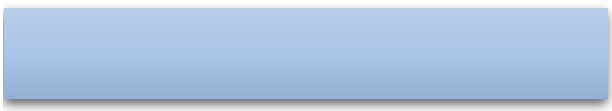

Series1, Kat.3:Non

diagnosed students, $30.6 \%$

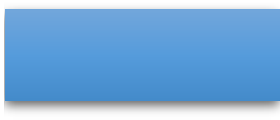

- Series1, Cat.2:The diagnosed students (not declared by the parents ), $13.9 \%$

Figure 2. The situation in the class (Topic 1; Cat. 1; Sub/Cat 1-3)

Again, for the first issue, in connection with teachers in their classrooms have students with disabilities for Cat. 2: -way working with students with disabilities identified in Sub / Kat have the results: Under/Cat. 1: - teachers working with students with disabilities Differential with IEP; and Under/Cat. 2: - teachers working with students with disabilities without IEP, have this appearance in \%

In connection with Cat. 4: - Adaptation of teaching according to the program, teachers are identified in three subcategories. Under/Cat. 1: -Adaption of teaching preschool program; Under/Cat. 2: Adaptation of teaching in class. 1-3; Under/Cat. 3: Adaptation of teaching in class 4-5. 


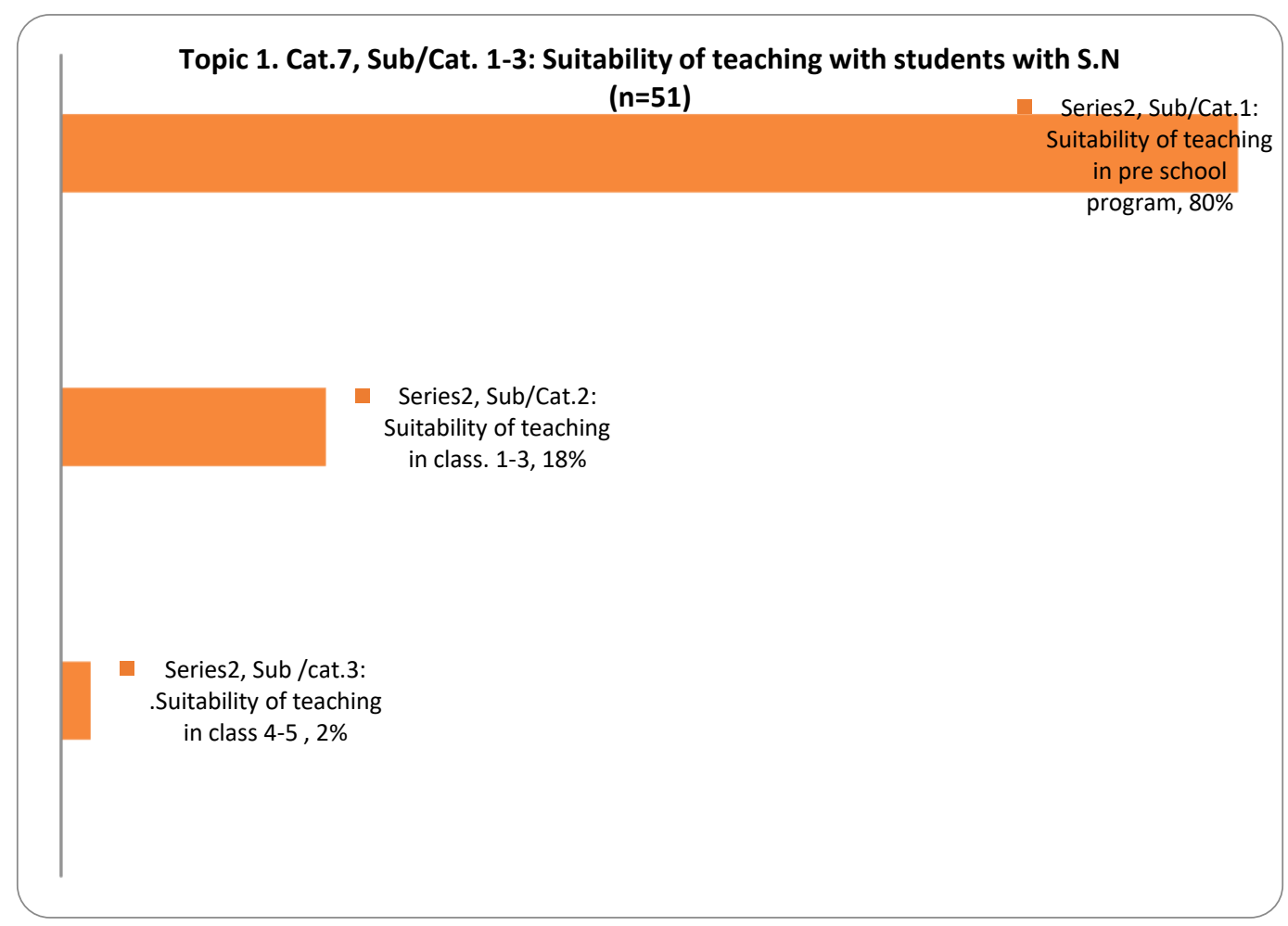

Figure 3. Opinions of the teachers about this suitability

Regarding the second theme, in relation to training for the recognition of Disability and "differentiated teaching" and contemporary, the results for the first category and the second are awarded based school.

For school (1) have this picture: for Cat. 1. - Teachers inclusive classrooms have no such training, $88 \%$ of teachers are untrained, accompanied by two sub/floor. relevant: Sub/Cat. 1: -Teachers comprehensive classes are not trained in the adaptation of teaching depending on the restrictions that disabled students and Sub/Cat. 2: -Teachers comprehensive classes are not trained in the use of new technology in teaching for these students. While Cat. 2: - Teachers are trained in inclusive classrooms, where in $13 \%$ of trained teachers were identified sub/categories: Under /Cat. 1:

In connection with The topic 4: Thoughts and suggestions on inclusive education in our schools, identified the following categories: Cat. 1: -Teachers accept inclusion but the fulfillment of certain conditions; Cat. 2: -Teachers accept inclusion in today's conditions; Cat. 3: -Teachers do not accept inclusion; Cat. 4: - Teachers are reluctant to provide their opinions/suggestions related to "inclusion" which are reflected in the chart below in\%: 


\section{The Topic 4: Opinions of teachers in inclusion $(n=51)$}

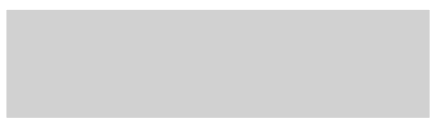

- Series1, Cat.4: The

teachers hesitate to

give opinions, $14 \%$

Series1, Cat.3: Don't agree , $33 \%$

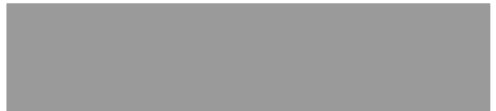

- Series1, Cat.2:

Agree, 16\%

\section{$\square \quad$ Series1, Cat.1: \\ Agree, but on some conditions , $37 \%$}

Figure. 4. Opinions of teachers in inclusion

\section{Conclusion}

What to fall in eye contact with teachers was that they wanted so much persistent training on the recognition of "Disabilities" and the "Teaching" for its adjustment depending on the capabilities and needs of these students .

Another element that required teachers to be completed was the device or the association of these students with specialist teacher or school psychologist. This "support" that teachers were asked about the "success" that they wanted in connection with the integration of these students in class. $23 \%$ of teachers expressed that they were unsupported, while $28 \%$ had support from: parent; school colleagues; psychologist or school administration. The rest of the teachers prefer not to provide an answer to this question.

$53 \%$ of teachers are in favor of inclusiveness but the fulfillment of certain conditions:

- Significant number of students per class (no more than 25-30 students in class);

- 1-2 students with A. K. in the classroom;

- Teacher or teacher support specialist "Disability"; 
- Support the multidisciplinary team and the school in relation to meeting the needs that may arise during the adaptation of teaching teachers.

While $47 \%$ of teachers do not agree with the inclusion of disabled students in general classrooms or showed indifference by not answering.

Positive comments about Kat. 4, where most favored is the adaptation of teaching preschool program, compared with Kl. 1-3 and even more difficult is its adaptation for grades 4-5. Relationship between the program and the adjustment goes in the opposite direction, as simple be so easy the program is to adapt and fewer problems also have classes where teaching adaptation is higher.

And about the fourth topic, where the teachers about inclusive education, even those who speak out against those who support inclusion, suggesting the implementation of inclusive education to the fulfillment of certain conditions that require the following classes: - supportive teacher or specialist; - Student with A. K. are not be burdened; - Limited number of students with disabilities (1-2), as also defined in the Normative Clause and multilateral

\section{Recommendations}

Recommendation 1. accurate diagnosis of children showing the degree of severity of "restriction", presenting it as well as their disclosure to school, makes teachers more accountable for teaching adjustment in terms of abilities and needs that presents the student;

Recommendation 2. Training on: drafting / s IEP implementation of comprehensive class teachers; on the recognition of disability types and differentiated teaching and the contemporary, makes teaching for those students most well studied in terms of objectives.

Recommendation 3. you include students with A. K. in ordinary classrooms must be accompanied by: supportive teacher / specialist; limited number of students with A. K. class (1-2);

Recommendation 4. Adaptation of teaching depending on the capabilities and needs of disabled students significantly increases efficiency and reduces teaching various problems that these classes.

\section{Bibliography}

[1] Prakash, S. S. (2012). Inclusion of Children with Hearing Impairment in Schools: A Survey on Teachers' Attitudes. Prakash. Vol. 23, No. 3, p 90-103.

[2] Subban, P \& Sharma, U. (2005). Educator Understanding Attitudes Toward the Implementation of Inclusive Education. Monash University, Melbourne, Victoria, Australia.

[3] Villa, R. A, \& Thousand, J. S. (2003). Making Inclusive Education Work. Teaching All Students, 61 (2), 19-23.

[4] Matthews. B \& Ross. L, (2010). "Research Methods", a practical guide to social sciences and humanities, publication of CDE, Tirana / Albani. P. 218-233.

[5] Avramidis, E. (2005). Developing inclusive SCHOOLS: Changing teachers' attitudes and Practices through Critical Professional Development. Inclusive and Supportive Education Congress, International Special Education Conference, Inclusion: Celebrating Diversity?

[6] Agbenyega, J. (2007). Examinining Teachers' concerns and attitudes to Inclusive Education in Chana. International Journal of Ëholeschooling. Vol. 3, No. 1, pp 41-56.

[7] Bagleri, S. \& Shapiro, A. (2012). Disability studies and the Inclusive Classroom Practices for Critical Attitudes Greating Least restrictive. ISBN: 978-0-415-99372-2, ISBN: 978-0-203-83739-9. 
[8] ADRIF. (2006). Study and Evaluation of Disability Legislation in Albania. Tirana: Swedish Helsinki Committee for Human Rights.

[9] Nano, V. (2001). "On the integration of children with special needs in mainstream schools of Italy". Pedagogical Magazine, 2, pp. 107-118.

[10] Nano, V. (2002). Albanian schools towards integration processes. ADRIF.

[11] Nicholas, H. , \& Alan, W. (2010). School experience influence on pre-service teachers about the effective Teaching evolving beliefs. Teaching and Teacher Education, pp. 278-289. 